В городах к органам исполнительной власти относились городские и участковые приставы, полицейские надзиратели, а также в столицах, крупных уездных и губернских городах - городские полицейские управления. Bce они были подведомственными уездному полицейскому управлению.

Основные направления деятельности органов исполнительной полиции в период с 1862 г. по 1880 г. и с 1880 г. по 1905 г. существенно не различались и включали организацию общественной безопасности и охрану общественного порядка в уездах, городах, иных населенных пунктах, контроля за исполнением законов, выполнением финансовых обязательств, инспектирование становых приставов, кадровое обеспечение деятельности самих полицейских органов, проведение оперативно-следственных мероприятий, участие в проведении дознания, охране прав верующих при осуществлении религиозных обрядов православной церкви, иных конфессий, и др.

$$
* * *
$$

1. Временные правила для действия полиции по предметам, оставленным в ее ведении до преобразования других частей управления. Проект // Материалы, собранные для высочайше учрежденной комиссии о преобразовании губернских и уездных учреждений: отдел полицейский. Ч. I. Отд. 2. - СПб.: Тип. 2 Отд-ния Собств. е. и. вел. канцелярии, 1870-1876 [Электронный ресурс]. Режим доступа: Российская государственная библиотека: http://search.rsl.ru/ru/record/01003859027.

2. Ерошкин, Н.П. Очерки истории государственных учреждений дореволюционной России: пособие для учителя / Н.П. Ерошкин. - М.: Государственное учебно-педагогическое издательство министерства просвещения РСФСР, 1960. - 396 с.

3. Ерин, Д.А. Организационные и кадровые реформы Российской полиции во второй половине XIX начале XX веков: Автореферат диссертации на соискание ученой степени кандидата юридических наук: 12.00 .01 / Д.А. Ерин. - М., 2000. - 26 с.

4. Толстая, А.И. История государства и права России: учебник для вузов / А.И. Толстая. - 3-е изд., стер. - М.: Юстицинформ: Омега-Л, 2010. - 320 с.

5. Министры внутренних дел: История МВД России [Электронный ресурс]. - Режим доступа: Официальный сайт Министерства внутренних дел Российской Федерации: https://мвд.pф/history/Ministri_vnutrennih_del.

6. Андреевский, И.Е. Русское государственное право / И.Е. Андреевский. Т. 1. Ч. 1. - СПб., 1866 [Электронный ресурс]. - Режим доступа: http://www.center-bereg.ru/l1641.html.

7. Положение о Земских Участковых Начальниках, Правила об устройстве судебной части в местностях, где действовало это положение (Положение II) (высочайше утв. 12 июля 1889 г.) // Полное собрание законов Российской империи. Собрание второе 2-е (1881-1913). - Т. 16. - 1892. - № 6196 [Электронный pecypc]. - Режим доступа: http://www.nlr.ru/eres/law_r/search.php?regim=4\&page=508\&part=1540.

8. Общее губернское учреждение (Изд. 1892 г.) // Свод законов Российской империи. Том второй. Часть первая. Свод губернских учреждений. - СПб., 1892 [Электронный ресурс]. - Режим доступа: http://constitutions.ru/?p=3227.

\title{
Лейко М.С. \\ Проблемные вопросы назначения и исполнения уголовного наказания в виде штрафа, пути их решения
}

Самарский наџиональный исследовательский университет имени академика С.П. Королёва (Россия, Самара)

doi:10.18411/spc-22-12-2017-09

idsp: 000001:spc-22-12-2017-09

В данной научной работе рассмотрены важные проблематичные вопросы о назначении, исполнении штрафа и предоставлены пути их решения. Исследованы характерные особенности применения штрафа в качестве альтернативного лишению свободы наказания, противоречия в законодательстве, стабилизирующие исполнение штрафа и последствие уклонения от уплаты штрафа.

В данный момент в Российской Федерации назначение уголовного наказания в виде штрафа представляется альтернативой лишению свободы. Под альтернативными наказаниями понимают меры правительственного принуждения, назначаемые судом 
как наказания, что никак не связано с изоляцией от общества, однако является ее адекватной заменой в связи с общественной опасностью содеянного и личностью виновного. Можно отметить три основных подхода к установлению свойства адекватности альтернативных наказаний. В соответствии $\mathrm{c}$ первой позицией, адекватными признаются наказания, приближенные в законодательном перечне видов наказаний к ограничению свободы на установленный срок. Так, в УК РФ, по состоянию на время принятия, система наказаний была дополнена обязательными работами, арестом и лишением свободы. Данное нововведение объясняется тем, что перечисленные наказания могут стать действительной альтернативой лишению свободы и назначаться лицам, совершившим преступления, за которые ранее следовало бы ограничение свободы. В соответствии с иной позицией альтернативные наказания это все виды наказания, которые предшествуют в законодательном перечне видов наказаний лишению свободы на определенный срок. Порядок назначения штрафа регламентирован ст. 46 УК РФ.

Под штрафом понимается денежное взыскание. Штраф устанавливается в размере от двух с половиной тысяч до одного миллиона рублей или в размере заработной платы или иного дохода осужденного за период от двух недель до пяти лет. Взыскание в размере от пятисот тысяч рублей или в размере заработной платы или прочего дохода осужденного за период свыше трех лет может назначаться только за тяжкие и особо тяжкие преступления в случаях, специально предусмотренных соответствующими статьями Особенной части УК РФ. Согласно содержанию штраф относится к наказанию материального характера. Исполнение уголовного наказания не связанно с лишением свободы. Виновного не лишают такого блага, равно как свобода, не отрывают от семьи, работы, учебы или другой общественной деятельности. В рамках своей самостоятельности может назначаться как основное, так и дополнительное наказание. Штраф исчисляется из основной заработной платы или иных доходах, суд вправе сам избирать причины его исчисления. Тем не менее данное утверждение стоит уточнить. Закон выделяет ряд преступлений, за совершение которых штраф может быть взыскан только из одного основания. Речь идет о назначении штрафа за преступления, связанные с предметом или суммой коммерческого подкупа, взятки или с суммой незаконно перемещенных денежных средств и стоимости денежных инструментов. В данных вариантах закон предписывает исчислять штраф только лишь отталкиваясь из кратной стоимости указанных предметов либо сумм. При исчислении штрафа с учетом кратной величины обязаны оставаться наименьшие значения, введенные для рассматриваемого метода исчисления наказания, а именно двадцать пять тысяч рублей. Следовательно, даже если сумма, вычисленная с учетом кратной величины, меньше двадцати пяти тысяч рублей, наименьший предел обязан быть соблюден и штраф назначается в размере двадцати пяти тысяч рублей. К примеру, в случае если перед судом стоит выбор назначения штрафа исходя из размера заработной платы или исходя из размера других доходов, суд имеет право выбрать любое основание его исчисления в том случае, если приговоренный получает заработную плату и у него есть иные доходы. Сочетание причин закон воспрещает. Так же предписанное ограничение только к одному способу исчисления размера наказания. Следовательно, в случае если, например, штраф, устанавливаемый в качестве основного наказания, был взыскан на основании величины заработной платы, в таком случае закон не запрещает в качестве дополнительного наказания вынести взыскание исходя из размера другого заработка осужденного.

Разберем актуальные проблемы назначения и исполнения уголовного наказания в виде штрафа. Законодатель считает взыскание наиболее мягким уголовным наказанием, и ставит его на первое место в перечень других уголовных наказаний перечисленных ст. 44 УК РФ. Является ли он самым мягким наказанием на самом деле, считается спорным вопросом, так как его размер, с учетом последних изменений, 
согласно ст. 46 УК РФ колеблется только в твердой денежной сумме в размере от пяти тысяч до пяти миллионов рублей. Для гарантий реального исполнения штрафа законодатель включает ч. 3 ст. 46 УК РФ обязанность суда при назначении уголовного наказания в виде штрафа учитывать имущественное положение осужденного и его семьи, а также возможность получения осужденным заработной платы или иного дохода. Без этого условия уголовное наказание в виде штрафа потеряет смысл.

В статье 31 УИК РФ осужденный обязан уплатить штраф в течение 30 дней со дня вступления приговора суда в законную силу. Если осужденный не в состоянии единовременно уплатить штраф, суд по его ходатайству может рассрочить уплату штрафа. Приговоренный к штрафу с рассрочкой выплаты, а кроме того приговоренный, в отношении которого суд установил решение о рассрочке уплаты штрафа, должны в течение 30 дней со дня вступления приговора или решения суда в законную силу оплатить первую часть штрафа. Остальные части штрафа приговоренный должен оплачивать каждый месяц никак не позже конечного дня каждого последующего месяца.

Рассматривая проблему этого наказания, можно сделать вывод, что законодатель Федеральным законом от 7 декабря 2011 г. № 420-ФЗ изменил положения о сроке рассрочки и отсрочки уплаты штрафа в УК РФ и в ст. 398 УПК РФ, определив его в пять лет вместо прежних трех, однако при этом ч. 2 ст. 31 УИК РФ не изменена и попрежнему указывает на три года. Такая ситуация ставит в запутанное положение осужденных к рассматриваемому наказанию. Этот вопрос можно разрешить путем соответствия срока рассрочки уплаты штрафа в уголовно-исполнительном законодательстве аналогичный уголовному законодательству.

Цель применения штрафа - решить кризисную ситуацию, сформировавшуюся в тюрьмах и уменьшить затраты на содержание осужденных. Основная задача штрафа предоставление правопорядка с помощью необходимого, но не избыточного принуждения и уменьшения показателей повторного преступления. Согласно статистике научных исследователей цели и задачи не выполняются.

В исследовании важных проблем рассмотрим столкновение гражданского и уголовного права при назначении и исполнении штрафа. На примере мнения Ю. В. Голика, который подмечает, что «штраф есть уголовное наказание и, поэтому, обязан нести определенный карательный заряд, однако в существующем сейчас воплощении по отношению к преступникам не достигшим совершеннолетия он является компенсационной мерой, а компенсационный характер имеет именно гражданскоправовая ответственность»[6].

Особо сложная проблема в исполнении наказания в виде штрафа возникает при решении вопроса, каким наказанием его заменить. В соответствии с ч. 5 ст. 46 УК РФ «в случае злостного уклонения от уплаты штрафа, назначенного в качестве основного наказания, за исключением случаев назначения штрафа в размере, исчисляемом исходя из величины, кратной стоимости предмета или сумме коммерческого подкупа или взятки, штраф заменяется иным наказанием, за исключением лишения свободы, в последнем случае он заменяется наказанием в пределах санкции, предусмотренной соответствующей статьей Особенной части, при этом назначенное наказание не может быть условным»[7]. «Злостно уклоняющимся от уплаты штрафа признается осужденный, не уплативший штраф в 30-дневный срок (ч. 1 ст. 32 УИК РФ)» [8]. В отношении осужденного, умышленно уклоняющегося от уплаты штрафа, определенного в качестве главного наказания, судебный пристав-исполнитель не ранее 10 , однако не позднее 30 дней со дня истечения максимального времени уплаты, направляет в суд представление о смене штрафа иным типом санкции (в соответствии с наказанием статьи уголовного закона, по которой назначено наказание). Помимо этого, в отношении осужденного, умышленно уклоняющегося от уплаты штрафа, определенного в качестве вспомогательного наказания, судебный пристав-исполнитель 
совершает взимание штрафа в принудительном порядке, предустановленном законодательством Российской Федерации. Умышленно уклоняющийся от отбывания наказания приговоренный, местоположение которого неизвестно, объявляется в розыск и может быть задержан на срок вплоть до 48 часов. Этот срок может быть увеличен судом вплоть до 30 суток. Решая вопрос о замене штрафа другим наказанием, суд должен учитывать ограничения, установленные для отдельных видов наказаний статьями Общей части уголовного закона. Таким образом, решение вопроса о виде наказания, которым можно заменить штраф, в первую очередь зависит от того, осуждено лицо за преступление, связанное с коммерческим подкупом и взяткой, или нет. Лишь в последнем случае возможна замена штрафа лишением свободы, и такой вариант исполнения приговора является предпочтительным, поскольку, как правило, осужденный, уклоняющийся от уплаты штрафа, не желает и не будет отбывать никакое другое наказание.

Как известно, метод установления штрафа в рублях был в уголовном законе вплоть до октября 1992 года, если либерализация цен и, как следствие, активное повышение инфляции требовали изменения порядка исчисления штрафа. Конституционный Суд Российской Федерации в одном из определений объяснил, что «применение базовой суммы (100 руб.) в качестве единицы расчета при определении размеров штрафа обуславливается потребностью предоставления соразмерности этого типа наказания тяжести совершенного правонарушения в обстоятельствах стремительно меняющейся покупательной возможности средств, при этом сама по себе перемена цифрового выражения наименьшего объема оплаты работы, констатируемого в конкретный момент с учетом совершающихся в стране инфляционных действий, никак не говорит об изменении его содержательной характеристики» [9].

В соответствии с ч. 2 ст. 88 УК РФ (в ред. Федерального закона от 08.12.2003 № 169-Ф3) «Штраф назначается как при наличии у несовершеннолетнего осужденного самостоятельного заработка или имущества, на которое может быть обращено взыскание, так и при отсутствии таковых. Взыскание, определенное не достигшему совершеннолетия осужденному, по решению суда может взыскиваться с его отца и матери или других законных представителей с их согласия. Штраф назначается в размере от одной тысячи до пятидесяти тысяч рублей или в размере заработной платы или иного дохода несовершеннолетнего осужденного за период от двух недель до шести месяцев»[10].

В соответствии с ч. 1 ст. 5 УК РФ, «лицо подлежит уголовной ответственности только за те общественно опасные действия (бездействие) и наступившие общественно опасные последствия, в отношении которых установлена его вина»[11]. Отец с матерью или иные законные представители не достигших совершеннолетия не делают никакого социально опасного, беззаконного, виновного и караемого действия, тем не менее, подвергаются наказанию из-за правонарушения, свершенные их несовершеннолетним ребенком или подопечными.

«В следствии подобного постановления законодателя появляется ситуация, при которой виновный в совершении правонарушения по сути отвиливает от наказания за совершенное им действие. А допустимо ли в данном случае достижение цели специальной превенции правонарушений? Конечно, нет. Та как предотвращение правонарушений со стороны лиц, их ранее совершавших, достигается, главным образом, непосредственно тем, что впоследствии осужденного удерживает от совершения правонарушения опыт изведанного наказания»[12].

Кроме того, согласно ч. 1 ст.43 УК РФ «Наказание есть мера государственного принуждения, назначаемая по приговору суда. Наказание применяется к лицу, признанному виновным в совершении преступления, и заключается в предусмотренных настоящим Кодексом лишении или ограничении прав и свобод этого лица»[13]. Еще в XIX столетии знаменитый российский ученый Н.С. Таганцев писал: «любое взыскание 
обязано являться страданием для виновного, страданием, им собственнолично отбываемым, закон никак не может позволить, чтобы назначенное кому-либо взыскание отбывалось за него иным лицом»[14]. Тем не менее, законодатель в функционирующей редакции ч.2 ст.88 УК РФ допускает вероятность использования меры принуждения к неповинной личности с его согласия.

Еще один вопрос может появиться с осуществлением штрафа, назначенного не достигшему совершеннолетия человеку, в случае если судебный процесс приведет к выводу о способности взимать штраф с родителей или других законных представителей несовершеннолетнего осужденного с их согласия. Бесспорно, при отсутствии у несовершеннолетнего заработка или собственности, на которое может быть обращено взимание, суды будут выносить приговоры, предусматривающие взыскание в виде штрафа, только лишь получив заблаговременное соглашение отца и матери либо других законных представителей виновного оплатить за него взыскание.

Однако ни УК РФ, ни УИК РФ правовые последствия отказа этих персон от уплаты штрафа никак не учтены. Нормы об умышленном уклонении от уплаты штрафа распространяются только лишь на самих осужденных, однако, никак не на их родителей и других законных представителей. Вынужденное взимание штрафа также возможно лишь в отношении самого осужденного и только в том случае, если взыскание назначено в качестве вспомогательного наказания (ч. 3 ст. 32 УИК РФ).

«При наступлении уголовной ответственности в отношении несовершеннолетних назначается психолого-психиатрическая экспертиза, которая является сложным видом исследования. Специалистами применяются различные психологические и медицинские тесты, итогом которых становится заключение экспертов о вменяемости или не вменяемости несовершеннолетнего на момент совершения преступления. Если несовершеннолетнего признали невменяемым, ему будет назначена принудительная мера медицинского характера, следовательно, наступление уголовной ответственности невозможно»[15].

Далее видится логичным рассмотреть сходства и различия назначения штрафа в России и Китае: «общим видом для этих стран является штраф, размер которого в УК РФ и УК КНР определяется судом с учетом тяжести совершенного преступления, с учетом возможности получения осужденным заработной платы или другого дохода или с учетом имущественного положения осужденного и членов его семьи. В Китайском законодательстве уточняется: «если по независящим от осужденного причинам своевременная уплата штрафа оказывается затруднительной, суд может принять решение об уменьшении размера штрафа, либо об освобождении от этого наказания». В действующем УК КНР штраф предусматривается в санкциях 150 статей. К примеру, к преступлениям, которые наказываются штрафом, относятся: преступления против собственности, преступления против порядка социалистического рынка, против общественного порядка и порядка управления. А в УК РФ штраф предусматривается за: преступления в сфере экономики, преступления против общественной безопасности, преступления против собственности и другие»[16].

Если рассмотреть назначение штрафов в Израиле, то становится очевидно, что: «В израильском уголовном законодательстве штрафы представлены в Главе далет. Размер штрафа зависит от тяжести преступления и срока тюремного наказания. Даже если в статье прямо не говорится о возможности назначения штрафа, суд вправе его назначить, в зависимости от тяжести преступления, если это входит в его компетенцию. Зафиксирован максимальный размер штрафа в виде денежной суммы в статье 61, либо предусмотрен штраф соответствии со стоимостью ущерба или выгоды в четырёхкратном размере в статье 63. Если виновный не уплатит штраф в установленный срок, суд вправе назначить ему лишение свободы на срок до трех лет вместо штрафа, но при этом тюремный срок вместо штрафа не должен превышать тюремный срок за категорию совершённого преступления. Уголовный кодекс России 
определяет штраф как денежное взыскание, назначаемое в пределах данного кодекса. Размер находится в зависимости от тяжести преступления, имущественного положения виновного лица, а также учитывается получение этим лицом заработной платы или иного дохода. Данный вид наказания может быть, как дополнительным, так и основным. Как мы видим, российские суды вправе назначать штрафы в качестве основного или дополнительного наказания только если это указано в статье особенной части. Израильским судам в этом плане предоставлено больше свободы при вынесении решений, однако законодательство Израиля нигде прямо не учитывает имущественное положение лица и его семьи, в отличии от Уголовного кодекса РФ. Также в законодательстве Израиля присутствует процентная надбавка за просрочку выплаты штрафа (ст. 67), что является дополнительным стимулом при его выплате. В обоих уголовно- правовых актах предусматривается возможность выплаты штрафа по частям»[17].

Многочисленные приговоры с назначением штрафа остаются невыполненными. Назначая взыскание в виде штрафа, судьи опираются на данных о личности, включая материальное положение подсудимого. Тем не менее, после постановления вердикта обстоятельства могут поменяться. К примеру, приговоренный может быть уволен, может заболеть и утратить в связи с этим трудоспособность на долгое время, его семейное положение может измениться, могут появиться новые обязанности по содержанию членов своей семьи и т.п. Принять к сведению всевозможные варианты развития событий нельзя. Закон никак не обязует судью это делать. Иное, может быть существенное объективное обстоятельство, препятствующее выполнению судебных решений о штрафе, - несовершенство законодательных предписаний об этом виде наказания. Качество практики назначения и исполнения штрафа непосредственно связано с качеством закона. Потому как подавляющая часть приговоров с назначенным штрафом остается без исполнения, отсюда следует вывод о том, что в УК РФ необоснованно расширены границы применения штрафа.

С целью успешного назначения и исполнения уголовного наказания в виде штрафа, а так же для решения выше обозначенных проблем требуется:

1) Обеспечить ответственность за злонамеренное уклонение от уплаты штрафа. Под этим следует понимать предумышленное несоблюдение осужденным обязанности по уплате штрафа либо части штрафа в установленные законодательством сроки при наличии у должника реальной возможности выполнить эту обязанность либо сознательное создание преград для исполнения штрафа.

2) Качественная оценка материального положения осужденного для гарантирования безусловности штрафа, то есть его реальное исполнение.

3) При назначении наказания в виде наказания принимать во внимание судом тяжесть совершенного правонарушения, состав правонарушения, характеристик личности виновного.

4) Существенно увеличить качество работы судебных приставов. В нынешнее время службу судебных приставов невозможно оценить на оценку «хорошо», так как не соблюдаются сроки процессуальных действий и не предпринимаются меры принудительного характера для исполнения наказания.

5) Для лиц не достигших совершеннолетия никак не целесообразно применять уголовное наказание в виде штрафа, следует заменять на обязательные работы, либо применять штрафные санкции с рассрочкой уплаты вплоть до 3 лет, для того чтобы виновный прочувствовал на себе бремя наказания.

6) Необходимо системно улучшать уголовное, уголовно-исполнительное и исполнительное законодательство, а кроме того Концепцию развития уголовноисполнительной системы Российской Федерации вплоть до 2020 г.

Штраф - это самое мягкое взыскание, предустановленное в законодательной системе наказаний. Согласно научным рекомендациям штраф в силу специфического 
характера заложенных в него карательных элементов рассчитан для применения его, во-первых, к тем лицам, которые совершают преступления не большой степени общественной опасности, а во-вторых, и к тем лицам, которые совершают и более серьезные правонарушения, но при наличии смягчающих и других обстоятельств. Штраф как альтернативный вид лишению свободы является одним из наиболее часто назначаемых уголовных наказаний. Принимая во внимание популярность применения штрафа, а кроме того желание повысить предупредительное воздействие данного вида наказания, норма, регламентирующая применение штрафа, зачастую довольно часто подвергается трансформации - изменяются наименьшие и наибольшие размеры штрафа, вводятся новые системы исчисления, уточняются положения о применении штрафа в зависимости от характера совершенных преступлений.

$$
* * *
$$

1.Головный кодекс Российской Федерации // СПС "КонсультантПлюс".

2. Уголовно-исполнительный кодекс Российской Федерации // СПС "КонсультантПлюс".

3. Федеральный закон от 02.10.2007 N 229-Ф3 (в ред. от 14 ноября 2017 г.) "Об исполнительном производстве" // СПС "КонсультантПлюс".

4. Дворянсков И.В. Эффективность альтернативных наказаний (компенсационная модель). М., 2014. С. $16,44-51$

5. Силантьев С.Д. Проблема штрафа в законодательстве и на практике // Вестник права. - 2016. - №63. - C. 15.

6. Голик Ю., Коробеев А. Прошлогодние трансформации уголовного закона: реплика // Уголовное право. 2013. № 2. С. 16-17.

7. "Уголовный кодекс Российской Федерации" от 13.06.1996 N 63-Ф3 (ред. от 29.07.2017) (с изм. и доп., вступ. в силу с 26.08.2017), ч. 5 ст. 46 УК РФ (часть 5 в ред. Федерального закона от 03.12.2012 N 231-Ф3)

8. "Уголовно-исполнительный кодекс Российской Федерации" от 08.01.1997 N 1-Ф3 (ред. от 16.10.2017), ч. 1 ст. 32

9. Коробеев А.И. Штраф // Уголовное право Российской Федерации. Общая часть: Учебник / Под ред. Л.В. Иногамовой-Хегай. М., 2016. С. 212.

10. Определение Конституционного Суда РФ от 11.12.2002 № 317-О «Об отказе в принятии к рассмотрению запроса президиума Московского окружного военного суда о проверке конституционности части первой статьи 46 УК РФ». Доступ из СПС «КонсультантПлюс».

11. "Уголовный кодекс Российской Федерации" от 13.06.1996 N 63-Ф3 (ред. от 29.07.2017) (с изм. и доп., вступ. в силу с 26.08.2017), ч. 2 ст. 88 (часть вторая в ред. Федерального закона от 08.12.2003 N 162-Ф3).

12. "Уголовный кодекс Российской Федерации" от 13.06.1996 N 63-Ф3 (ред. от 29.07.2017) (с изм. и доп., вступ. в силу с 26.08.2017), ч. 1 ст. 5.

13. Анденес И. Наказание и предупреждение преступлений. - М., 1979. С. 149.

14. "Уголовный кодекс Российской Федерации" от 13.06.1996 N 63-Ф3 (ред. от 29.07.2017) (с изм. и доп., вступ. в силу с 26.08.2017), ч. 1 ст. 43.

15. Таганцев Н.С. Русское уголовное право. Часть общая.- М., 1994. Т. 2. С. 273.

16. Баринова О.Д., Волкова Н.А. Уголовная ответственность несовершеннолетних // Актуальные вопросы юридических наук в современных условиях, Санкт-Петербург: Инновационный центр развития образования и науки, 2017. С. 53-54.

17. Боклина О.А., Волкова Н.А. Сравнительно-правовой анализ видов наказания в уголовном законодательстве РФ и уголовном законодательстве Китая // Актуальные вопросы юридических наук в современных условиях, Санкт-Петербург: Инновационный центр развития образования и науки, 2017. С. 55-56.

18. Волкова Н.А., Исаев М.С. Сравнительно-правовой анализ видов наказания в уголовном законодательстве России и Израиля // Сборник научных трудов по итогам международной научнопрактической конференции "Актуальные вопросы юридических наук в современных условиях", Санкт-Петербург: Инновационный центр развития образования и науки, 2017. С. 62-65. 